\title{
Desperately Seeking the Tools of Ethics for Traditional Medicine
}

\author{
Ishmael D. Norman ${ }^{1,2,3}$ \\ ${ }^{1}$ School of Public Health, (Hohoe Campus) University of Health and Allied Sciences, Ho, Ghana \\ ${ }^{2}$ Institute for Security, Disaster and Emergency Studies Sandpiper Place, Langma, Ghana \\ ${ }^{3}$ African Academy for Environmental Health, (AAEH) University of Malawi, Chichiri Blantyre, Malawi \\ Email: ishmael_norman@yahoo.com
}

Received 19 May 2016; accepted 25 July 2016; published 28 July 2016

Copyright (C) 2016 by author and Scientific Research Publishing Inc.

This work is licensed under the Creative Commons Attribution International License (CC BY).

http://creativecommons.org/licenses/by/4.0/

(c) () Open Access

\begin{abstract}
Objective: To determine the perceived adequacy of the Code of Ethics of the Traditional Medicine Practice as contained in Act 575 of 2000, with respect to patient and manufacturer protection. Method: The author reviewed the legal framework for the regulation of Traditional medicine in Ghana. Investigation was conducted on the worldwide web to identify literature that addressed the research question and reviewed for best practice. Result: The Code of Ethics of the Traditional Medicine Council of Ghana is inadequate for client and manufacturer protections. It is a professional code of ethics, which is skewed to industry players. This vacuum provides opportunity for mistakes, patient endangerment and even fatality. Discussion: There is an established national legal framework for the regulation of the industry with the secondary function of the taxonomy under the framework towards enhanced taxcollection by government. Patient protection code of ethics needs to be developed. Conclusion: The Council needs to develop the ethical framework that would protect both the ultimate beneficiaries of their products and services as well as the workers and operators in the industry.
\end{abstract}

\section{Keywords}

Code of Ethics, Traditional Medicine, Consumer Protection, Ghana

\section{Introduction}

This review is necessitated by the fact that although there appears to be a code of ethics for the practice of traditional medicine in Ghana, what exists is a list of do's and don'ts for the manufacturers and practitioners of the products used and services rendered in TM. Professional code of ethics is designed to protect and safeguard the members of that profession but not the beneficiaries and consumers of the products and services of that particular 
profession (Beauchamp \& Childress, 2001; Castellano Marlene, 2004). The literature review would start with the consideration of the legal framework. The legislations implicated in this exercise are: the Traditional Medicine Practice Act of 2000 (Act 575), the Code of Ethics and Standards of Practice for Traditional and Alternative Medicine Practitioners in Ghana, and the Ghana Health Service's Patient Charter contained in the Public Health Act of 2012 (Act 851). This evaluation would be done in relation to the research questions, which are namely: What protections are offered by these legislations forming the legal framework for the patient or ultimate user of the products of Traditional Medicine, (TM)? How are the manufacturers of TM products protected as a matter of public policy?

These pieces of legislations would be set against the principles and tools of biomedical ethics used and applied routinely to govern the patient-physician relationships as articulated by Feldman (1978); Dworkin (1988); Emmanuel and Emmanuel (1992); Brett (1997); Coughlin et al. (1999); Beauchamp and Childress (2001); Gostin (2002); Holland (2005); Katz et al. (2006); and Castellano Marlene (2004). The patient-physician relationship assumed in this paper includes the implied functions of pharmacists, and with overarching linkage to the manufacturer of pharmaceuticals and supplies normally implicated in the patient care.

\section{Method}

The author searched databases for reports, editorials and published papers in the English Language Traditional Medicine Practice. A search on Goggle Scholar provided the following pieces of legislations: the Traditional Medicine Practice Act of 2000 (Act 575), the Code of Ethics and Standards of Practice for Traditional and Alternative Medicine Practitioners in Ghana, and the Ghana Health Service's Patient Charter contained in the Public Health Act of 2012 (Act 851). There is a plethora of publication on TM in general but not in with specific focus on the ethical standards surrounding the practice and the protection of the consumer of TM products. With the exception of a handful of publications on TM as a general matter of inquiry, many of what was found were not helpful to the topic. Hand searching of selected printed journals and grey literature such as technical reports, conference proceedings and workshops as well as reported Court cases were also assessed.

For the research question the author used search combinations of "Code of Ethics for TM practice, Ghana"; or "Interpretation of TM Practice law, Ghana only"; "public health legislation on TM, Ghana, only"; "traditional rules/ethics on TM"; "Ghana medical ethics on TM", "privacy issues in TM law".

The volume of material on Ghana law were so few that almost all the literature identified were read, even if they did not related to the topic per se. Therefore, there was no need to establish inclusion criteria for any of the reports (scholarly paper, opinion, editorial, book chapter, internal post-operations reports, and annual reports) on the matter. Published papers such as those cited in this paper were read, assessed and applied to the research questions of this work.

\section{Result and Discussion}

\subsection{Definition of Traditional Medicine (TM)}

a) The Traditional Medicine Practice Act of 2000 defines TM as: "Practices based on beliefs and ideas recognized by the community to provide health care by using herbs and any other naturally occurring substances". It also defines herbal medicines as "any finished labelled medicinal products that contains as active ingredients aerial or underground parts of plants or other plant material or the combination of them, whether in the crude state or as plant preparation. Herbal medicines may also contain excipients in plant material in addition to the active ingredient and in exceptional cases may also contain natural organic or inorganic ingredients which are not of plant origin".

b) The World Health Organization defines TM as "Traditional medicine refers to health practices, approaches, knowledge and beliefs incorporating plant, animal and mineral based medicines, spiritual therapies, manual techniques and exercises, applied singularly or in combination to treat, diagnose and prevent illnesses or maintain well-being” (WHO Factsheet No. 134, 2003).

These rather liberal definitions of traditional medicines were intended to encourage the development of the discipline and expand its growth by practitioners who may have the indigenous knowledge and know-how about medicinal preparations but with limited capital and education. Notice that apart from the institutional and governmental encouragement of the industry, there is virtually no oversight from product development to distribution to the consumer in the general stream of commence with respect to efficacy issues or even adverse effect 
complications. What this means is that anyone who claims or want to claim that he or she possesses specialized knowledge about the preparation of certain potion can label it "traditional medicine" and perhaps get away with such a claim. Human nature being what it is, coupled with greed and profit-seeking behavior of makers of merchandise of any kind, there is a real attraction for a portion of the producers of traditional medicine to concoct non-beneficial potion, snake oil, so to speak, and claim such a product as either a prophylactic or a cure for a given ailment. The fact underscores the importance of this paper: for majority of the populations of the respective African nations, TM is their first choice of prophylactics and treatment (Norman, 2016).

There is a growing acceptance of African Traditional medicine and its practice. The World Health Organization offers that traditional medicine's use is growing in just about every geographical area of the earth. "For resource deprived and mismanaged nations in Africa, traditional medicine is a primary life saver" (Norman, 2016). The WHO asserts that,

Countries in Africa, Asia and Latin America use traditional medicine (TM) to help meet some of their primary health care needs. In Africa, up to $80 \%$ of the population uses traditional medicine for primary health care. ...In Ghana, Mali, Nigeria and Zambia, the first line of treatment for $60 \%$ of children with high fever resulting from malaria is the use of herbal medicines at home. ...In San Francisco, London and South Africa, $75 \%$ of people living with HIVIAIDS use TM. ...The global market for herbal medicines currently stands at over US $\$ 60$ billion annually and is growing steadily (WHO Fact sheet $N^{\circ} 134$, Revised May 2003).

\subsection{The Function and Mandate of the Traditional Medicine Practice Council}

The mandate of the Traditional Medicine Practice Council, (TMPC) is stated in Section 2 of the establishment Act, The Traditional Medicine Practice Act, 2000 (Act 575) that;

1) The object of the Council is to promote, control and regulate traditional medicine practice.

2) For the purposes of Section (1) the Council shall;

a) Set standards for the practice of traditional medicine;

b) Issue a certificate of registration to a qualified practitioner and license premises for a practice;

c) Determine and enforce a code of ethics for traditional medicine practice in conjunction with an association of traditional medicine practitioners recognized by the Minister responsible for health;

d) Promote and support training in traditional medicine;

e) Approve in consultation with educational and research institutions determined by the Board the curriculum for training in traditional medicine in the institutions,

f) Collaborate with the Ministry to establish centres for provision of traditional medical care within the national health care delivery system;

g) Advise the Minister on matters relating to and affecting the practice of traditional medicine;

h) Collaborate with appropriate agencies for large scale cultivation of medicinal plants and for the preservation of bio-diversity;

From its mandate and like all other agencies similarly situated, the core function of Act 575 of 2000 is to protect, regulate and organize TM practice and practitioners. Professional code of ethics may work well within the norms of that practice but may not meet the higher ethical expectations of society as a whole (Emmanuel \& Emmanuel, 1992; Brett, 1997; Coughlin et al., 1999; Beauchamp \& Childress, 2001; Holland, 2005; Rothstein, 2010).

Perhaps, it would be in good order to place the meaning of ethics in context of this narrative. Ethics is the philosophical study of the moral value of human conduct and of the rules and principles that ought to govern it. Ethics is a generic term of understanding and examining moral life. It is therefore synonymous with the term "morality" (Beauchamp \& Childress, 2001). A Professional Code of Conduct is often a list of administrative and convenient regulations or do's and don'ts. They do not, often, meet strict legal definition of “ethics" or even 'morality. Usages and customs among members of a profession, involving their moral and professional duties toward one another, toward clients, and towards the oversight and licensing organization of that profession, is, by and large, for the exclusive benefit of the members of that profession such as a nation's Bar Association or Medical and Dental Council (Kraushaar v. La Vin, 1818). Morality is concerned with human conduct or behavior. It is the distinction between good and bad, between what is right and wrong (Engstrom, 1992). Morality also 
means the quality of being moral, the degree of conformity to conventional standards of moral conduct. Moral Philosophy deals with both argument about the content of morality and meta-ethical discussion of the nature of moral judgment, argument and value (Coughlin, 1999; Beauchamp \& Childress, 2001; Gostin, 2002; Katz et al., 2006; Holland, 2010). For a professional code of ethics to attain a high level of ethical fitness or moral fitness, the code has to transcend mundane professional safeguards and due process protections of its members (Fletcher et al., 2005). Such a code would have to reach for a universal and an equitable parameter that safeguards all, without regard to professional status or group identity (Feldman, 1978; Dworkin, 1988).

This narrative would now focus on the Code of Ethics and Standards of Practice for Traditional and Alternative Medicine Practitioners in Ghana. Later in the course of this work, the discussion would focus on the Ghana Health Service's Patient Charter contained in the Public Health Act of 2012 (Act 851). This would thus enable the assessment whether it does or does not provide rights and privileges as well as responsibilities to patients of TM. The objective of the Code is as follows:

The Code of Ethics and Standards of Practice is aimed at instilling discipline and professionalism into traditional medicine practice, thus serving as a regulatory instrument for traditional medicine practice in Ghana.

As already observed, the primary goal of the Code of Ethics of TMPC is the protection of its members. The following sections from the Code of Ethics of TMPC appears to share commonality of impetus with the spirit of biomedical ethics in terms of the protections of patients. In Article 9 of the Code the TM practitioner is required to report adverse effects of their medications and other products such as suppositories, pomades and lotions:

Article 9: Traditional Medicine Practitioners shall immediately report any observed undesirable reactions and side effects noted in the course of the treatment to the national centre for Pharmacovigilance or any other body as determined by the council.

There are many Articles of the Code of Ethics of TM that read like a list of moral admonitions rather than a strict code of ethics for medical practice. This statement is illustrated in Article 16 as quoted below. A strict code of ethics that is supposed to govern the practitioner-patient relationship would not include statements on mundane behavior such as admonitions against drunkenness, smoking, immorality, abuse of drugs and pilfering. The practice of Traditional Medicine is not about morality but about healthcare delivery services and products in quasi-clinical environment. A so-called immoral medical practitioner who is at the top of his or her professional competencies and delivers first class medical services to his or her patients would not be considered unfit to render services to his or her clients provided such behavior did not impair his or her ability to render the needed services. The kind of immorality mentioned here needs to be defined in order to make it contextual. If the practitioner is drinking on the job, fondling patients, or stealing their money when they are being examined, these acts would not fall under immorality per se but rather something else. Such acts would be considered as either unprofessional in the case of drunkenness or criminal and tortious in the case of stealing clients' money or fondling clients. In the same vein, a traditional medicine provider could be a complete drunk but still provide top-notch potions that may be found to be efficacious and safe, provided his or her drunkenness does not interfere with the production of the potion whereby safety is compromised and efficacy is rendered null. Such fanciful, even comical dictates of the Code of Ethics for TM Practitioners are produced here for review and beginning from Article 16 through 20 of the Code:

Article 16: Traditional Medicine Practitioners shall refrain from all acts of indiscipline including drunkenness, smoking, immorality, abuse of drugs and pilfering in the course of performing their duties.

Article 17: Traditional Medicine Practitioners shall neither prescribe any medicine(s) made from or containing parts of the human body or organs nor indulge in human sacrifices.

For a manufacturer of medicines to even think of using human body or organs or indulge in human sacrifices as articulated in Article 17 of the Code, takes such a behavior out of the core functions of even traditional medicine preparations into another realm, where criminality, bestiality and superstition thrive. The rest of the set of moral code to the practitioner of TM underscores the need to develop modern rules of engagement for the practitioner of TM.

Article 18: Traditional Medicine Practitioners shall accept compensation only in-cash and in kind excluding 
human beings, their parts, sex and other socio- culturally unacceptable and illegal forms of practices.

Article 19: Traditional Medicine Practitioner shall exclude sexual activity as a form of treatment of any ailment whatsoever, either physical or spiritual. She/he shall also avoid sexual harassment in the course of duty. Clients shall be exposed or undressed in a manner deemed decent only in the presence of a relative or chaperon.

Article 20: Preparations used shall be done under the license and supervision of a qualified and registered Traditional Medicine Practitioner. Good Manufacturing Practices (GMP) shall be strictly adhered to, in order to ensure quality.

It is only in Articles 34 through 39 that one glimpses a superficial compliance with universal biomedical code of ethics of beneficence, non-malfeasance, due process, privacy and informed consent by TM practitioners.

That is to say, neither the Traditional Medicine Practice Act of 2000 (Act 575) nor the Code of Ethics of Traditional Medicine Practitioners provide adequate protections for the safety, privacy, practitioner-patient confidentiality, truth-telling, autonomy, respect, responsibility, security and choice of the patient. The protocol of TM practice is erected on paternalistic platform, which is shrouded in mysticism.

The Tradition Medicine Practice Act of 2000 (Act 575) places TM under the oversight responsibility of the Ministry of Health and by extension, the Ghana Health Service under Section 2 (f) thus: Collaborate with the Ministry to establish centres for provision of traditional medical care within the national health care delivery system. Therefore, TM comes under the Ghana Health Service's Patient Charter as articulated in the Sixth Schedule, Section 167 of the Public Health Act, 2012 (Act 851). That is to say, in so long as TM joins the stream of health care delivery system operated by the Ghana Health Service, it is assumed TM comes under Ghana Health Service operational responsibilities. Such a reading of the situation places a greater burden of responsibility on TM practitioners, whose training and education cannot be compared to that of practitioners of orthodox medicine under the Ghana Health Service modalities. This is not to say that the training of TM practitioner is inferior to a formally trained doctor either. What is of concern here is that to place TM practitioners under the same professional standard as those trained for orthodox medicine is to ignore the different mandates and establishment law that created the two systems. The two systems were created to have a binary effect: separate, different, but with the inherent right to operate in the general stream of the health care delivery system of Ghana with the view to preventing diseases, prolonging lives, and promoting the health of the populations and the sick.

\section{Conclusion}

Traditional Medicine is an important addition to choice for health interventions in Ghana. This is particularly so amongst the financially and economically vulnerable populations in the urban, peri-urban and rural areas. For the well to do segment of the population, TM is an alternative to orthodox medicines. The financially vulnerable cohort of the population of not only Ghana but the vast Sub-Saharan Region of Africa, tends to be more gullible, although not more so than the general population. But due to their economic powerlessness, they tend to believe in the misrepresentation of peddlers of pain killers in commercial vehicles plying the major routes. They buy such drugs and prophylactics of all kinds for all types of ailments, whether they are approved by the licensing authorities or not, without hesitation. They also buy at the street level. The social acceptance of medicine sellers and therefore the level of trust extended to them appear so high that the average consumer respects them as knowledgeable about matters of medicines. The majority of the consumers in the market of traditional medicines in Ghana, are within this cohort. It is for this reason and others articulated in this paper that the ethical regime of TM should be strengthened. By the very antecedents of the vast majority of the consumers of TM, there appears to be more reliance on the recommendations of the care giver. In TM there is no line, or diversification between the care giver and the drug manufacturer. The care giver in many instances is the drug-maker. Where there is diversification, the middle men or other players in the supply chain management and the retailers operate as proxies for the brand manufacturers. The situation could create an environment that is susceptible to corruption. Product puffing and over-representation of the efficacy of product and other material facts about the safety of product are common features of sales promotion by some of the purveyors of TM products. A good ethical framework for the industry would go a long way to safeguard the protections of consumers and manufacturers as well as workers in the industry. 


\section{References}

Beauchamp, T. L., \& Childress, J. F. (2001). Principles of Biomedical Ethics (5th ed.). Oxford: Oxford University Press.

Castellano Marlene, B. (2004). Ethics of Aboriginal Research. Journal of Aboriginal Health, 1, 98-114.

Code of Ethics and Standards of Practice for Traditional and Alternative Medicine Practitioners in Ghana. Accra: Government Printers.

Coughlin, S. S., Katz, W. H., \& Mattison, D. R. (1999). Ethics Instruction at Schools of Public Health in the United States. Association of Schools of Public Health Education Committee. American Journal of Public Health, 89, 768-770. http://dx.doi.org/10.2105/AJPH.89.5.768

Dworkin, G. (1988). The Theory and Practice of Autonomy. Cambridge, UK: Cambridge University Press. http://dx.doi.org/10.1017/CBO9780511625206

Emmanuel, E. J., \& Emmanuel, L. I. (1992). Four Models of the Physician-patient Relationship. JAMA, 267, 2221-2226. http://dx.doi.org/10.1001/jama.1992.03480160079038

Engstrom, S. (1992). The Concept of the Highest Good in Kant’s Moral Philosophy. Philosophy and Phenomenological Research, 51, 747-780. http://dx.doi.org/10.2307/2107910

Feldman, F. (1978). Kantian Ethics from His Introductory Ethics (pp. 97-117). New York: Prentice-Hall.

Ghana Health Service's Patient Charter Contained in the Public Health Act of 2012 (Act 851). Accra: Government Printers.

Gostin, L. O. (Ed.) (2002). Public Health Law and Ethics: A Reader. Berkeley, CA: University of California Press and the Milbank Memorial Fund.

Holland, S. (2010). Public Health Ethics (p. 50). Cambridge, UK: Polity Press.

Katz, R. V., Kegles, S. S., Kressin, N. R., et al. (2006). The Tuskegee Legacy Project: Willingness of Minorities to Participate in Biomedical Research. Journal of Health Care for the Poor and Underserved, 17, 698-715.

Kraushaar v. La Vin, 1818 Misc. 508, 42 N. Y. S. 2d, 857, 859.

Norman, I. D. (2016). The Tools for Appraising Ethics for the Practice of African Traditional Medicine. Acta Bioethica, (Accepted, 14 May, 2016).

Rothstein, M. A. (2009). Improve Privacy by Eliminating Informed Consent? IOM Report Misses the Mark. Journal of Law, Medicine \& Ethics, 37, 507-509. http://dx.doi.org/10.1111/j.1748-720X.2009.00411.x

Rothstein, M. A. (2010). The Hippocratic Bargain and Health Information Technology. Journal of Law, Medicine and Ethics. 38, 7-13. http://dx.doi.org/10.1111/j.1748-720X.2010.00460.x

Traditional Medicine Practice Act of 2000 (Act 575). Accra: Government Printers.

\section{Submit or recommend next manuscript to SCIRP and we will provide best service for you:}

Accepting pre-submission inquiries through Email, Facebook, LinkedIn, Twitter, etc.

A wide selection of journals (inclusive of 9 subjects, more than 200 journals)

Providing 24-hour high-quality service

User-friendly online submission system

Fair and swift peer-review system

Efficient typesetting and proofreading procedure

Display of the result of downloads and visits, as well as the number of cited articles

Maximum dissemination of your research work

Submit your manuscript at: http://papersubmission.scirp.org/ 